\title{
Barriers to Utilization of Sexual Health Services among Young People in District Dang Nepal:A Qualitative Study
}

PRAYAS GAUTAM, ${ }^{1}$ MUNAWAR HUSSAIN SOOMRO, ${ }^{2,3}$ SUPRICH SAPKOTA, ${ }^{4}$ KOSHISH RAJ GAUTAM, ${ }^{5}$ AASTHA KASAJU 6

\begin{abstract}
:
Background: Sexual behavior of young people is becoming one of the important social and major publichealth concerns in recent years. Despite the large population of young people, their needs receive limited programmatic and policy attention. Youth-friendly sexual and reproductive health services are lacking despite the existence of national guidelines that call for youth-friendly services. The aim of this study was to determine the barriers to utilization of sexual health services among young people of Badi community of Nepal.

Materials \& Methods: This qualitative study included the young people, 15-24 years of age among the Badi community in district Dang Nepal. We conducted 22 in-depth interviews by using the interview guideline among the young people. Written and verbal informed consent was taken from each research participants before data collection.

Results: Fourteen of the participants were males and eight were females. Participants were divided into two age groups: 15-19 and 20-24 and there were eight and fourteen participants from each group respectively. Rural participants were not satisfied with the services provided to them. We observed that discrimination, beliefs of society and feeling of shame towards family norms, lack of information about existing services, poor gender friendly services, lack of privacy and confidentiality and poor availability of the services pose the barriers to utilization of the sexual health services.

Conclusions: Communities should be provided with educational programs on sexual health through community based organization and the establishment of youth friendly service centers with easy access to communities in urban as well as in rural areas would encourage young people to use sexual health services more frequently.
\end{abstract}

Key words: Young People, Badi Community, Service Utilization, Sexual Health, Nepal, Qualitative Study.

DOI: http://dx.doi.org//0.3329/jom.v19i2.37224

1. Department of Public Health, Nobel College Sinamangal, Pokhara University, Kathmandu, Nepal.

2. Sorbonne Universités, UPMC Univ Paris 06, INSERM, Pierre Louis Institute of Epidemiology and Public Health (IPLESPUMRS 1136), Epidemiology of Allergic and Respiratory Diseases Department (EPAR), Saint-Antoine Medical School, 75012 Paris, France.

3. Department of Community Medicine, Al-Nafees Medical College, Isra University-Islamabad Campus, Pakistan.

4. Nepal Public Health Foundation, Maharajgung, Kathmandu, Nepal.

5. Department of Public Health,K.S Hegde Medical Academy, Nitte University, Karnataka, Manglore, India.

6. Little Buddha College of Health Science, Baneshor, Purbanchal University, Kathmandu, Nepal.

Corresponding Author: Dr. Munawar Hussain Soomro, Sorbonne Universités, UPMC Univ Paris 06, INSERM, Pierre Louis Institute of Epidemiology and Public Health (IPLESP UMRS 1136), Epidemiology of Allergic and Respiratory Diseases Department (EPAR), Saint-Antoine Medical School, 75012 Paris, France. Email: munawar.soomro@iplesp.upmc.fr.

Received: 08 May, 2017;

Accepted: 29 October, 2017

\section{Introduction:}

The sexual behavior among young people is becoming one of the most important and emerging issue in the field of public health. Age, sex, marital status and economic status of the young people have a great impact on the sexual health need of the young people. Different problems such as sexually transmitted infections (STIs) and unintended pregnancies may result due to unprotected sex. ${ }^{1}$ Young people have the right to get the sexual health services but due to the inaccessibility of information and friendly reproductive and sexual health services, young people are still not able to get proper health services. ${ }^{2-4}$ In Nepal, most of the sexual health services are provided by local health pharmacist, public health practitioners, doctors, nurses and community health workers. Provision of sexual and reproductive health services is poorin rural communities of Nepal. On the other hand, issues and topic related to sex and sexuality is still considered as a taboo in Nepal and other countries. ${ }^{2,5-7}$ In a cultural and traditional society like Nepal, issues related to sex and sexuality are still rigid and such issues are not easily 
expressed and discussed in the family and society in Nepal. In Nepal, 36 percent of people are aged 10-24 years. ${ }^{8}$ Despite of the more proportion of young population in Nepal, their needs and issues are not incorporated well in the programs and policy. Young people are facing many obstacles and challenges regarding their sexual and reproductive health and rights, 12 percent people living with Human Immunodeficiency Virus (HIV) are young between ages 15 to 24 years in Nepal. ${ }^{9}$

The Badi community is one of the country's most deprived and marginalized groups. The total population of the Badi people is 38,603 in Nepal according to National census $2011 .^{10}$ The economic status of the Badi community is not good enough so they are compelled to earn their living as commercial sex workers. ${ }^{11}$ Even now 6 percent of the women of Badi communities are involved in sex trade despite of the declaration of end of prostitution within the community by the government. ${ }^{12}$ However, the rising awareness among Badi community, they are slowly transforming and adapting other means of livelihood and shifting away from their traditional profession.

The adolescents are viewed as being an undeserved group when accessing Sexual and Reproductive Health Services (SRHS) in developing countries. ${ }^{3}$ The adolescents have sexual health needs which require special attention. Hence, there is a need for SRHS that are accessible, appropriate and acceptable to significantly meet the sexual and reproductive health needs of the adolescents. ${ }^{13}$ Due to social and cultural issues, sexual health research among young people in Nepal is still limited. ${ }^{14}$

This study was conducted to evaluate the updated situation and barriers to sexual health services among young people of Badi community of Nepal.

\section{Materials \& Methods:}

A cross-sectional, qualitative study was carried out in district Dang-Nepal during the period of September-October 2014. District Dang is situated in mid-western part of the country with an area of 2,995 Sq.Km and population of 5, 84,141. ${ }^{10}$ The study population was young people of either sex between 15 to 24 years of age among the Badi community. The Badi community is one of the country's most deprived and marginalized groups.

Purposive sampling technique was used to conduct in-depth interviews. A pre-designed questionnaire with open and closed ended questions was used. Questionnaire was prepared in English language and was translated in local Nepali language. Twenty two (22) in-depth interviews were conducted until saturation point was achieved. The entire interviews were audio recorded by using the digital recorder, which were then translated to English, transcribed verbatim, coded and were categorized into main themes. Validity and reliability was done by extensive literature review and followed by consultation with experts while developing of interview guidelines. For the ease, guideline was also translated in Nepali language. The study was approved by the Nobel College Sinamangal, Kathmandu, Nepal before collection of the data. Confidentiality was ensured by not disclosing the identity of participants and written as well as verbal informed consent was obtained from all patients. Participants were informed of their full right to skip or ignore any guidelines or terminate their participation at any stage of the study.

All the interviews were conducted by the principal author. Nepali language was used for interviews, which allowed communication between the researcher and information provider and this also reduced the misunderstanding between the interviewers and interviewees. Thus, if the interviewee did not understand the question, the researcher could explain the question and obtain relevant data.

\section{Results:}

The socio-demographic characteristics of the study participants are shown in the table I. Among 22 participants interviewed, 14 were male. Participants were divided into two age groups: 15-19 and 20-24 and there were eight and fourteen participants from each group respectively. Thirteen participants were married. Majority had secondary or higher education, while only two participants had primary education.

Table I

Socio-demographic characteristics of the study participants

\begin{tabular}{lc}
\hline Characteristics & Number \\
\hline Age (years) & \\
- $15-19$ & 8 \\
- $20-24$ & 14 \\
Sex & \\
- Male & 14 \\
- Female & 8 \\
Marital status & \\
- Married & 13 \\
- Unmarried & 9 \\
Level of education & \\
- Primary (1-5) & 2 \\
- Secondary(6-10) & 11 \\
- SLC pass or above (more than 10 grades) & 9 \\
Occupation & \\
- Student & 8 \\
- Job (Non-government organization) & 4 \\
- Farmer & 2 \\
- Housewife & 3 \\
- Tailor & 3 \\
- Musical instrument maker & 2 \\
\hline
\end{tabular}




\section{Perception on existing sexual health services:}

Most of the participants were from rural areas, were not satisfied with the services provided to them. They felt that most of the services were available in urban area and they had to travel a lot to reach services centers in urban areas and services which are available at health posts are not enough.

\section{Major factors influencing the barriers to utilization of sexual health services:}

The major themes identified in the data were:

- Discrimination, belief of the society and feeling of shame towards family norms,

- Lack of information about existing services,

- Poor gender friendly services,

- Lack of privacy and confidentiality, and

- Poor availability of the services.

Discrimination, belief of the society, feeling of shame towards family norms:

Most of the youth did not like to discuss the issues related to sexual health and sexual health problem openly in the society. This was due to the attitude of the society and fear of discrimination by the society. Youths also did not like to share their problems to their elders and the other family members due to parental attitude and norms of family.

\section{Lack of information about the services:}

Most of the participants felt that they lack information about the sexual health services provided to them. They did not know the all facilities that might be accessible to them to their nearest health centre.

\section{Poor gender friendly services:}

The participants felt uncomfortable to share about the problems related to sexual health with the service provider with opposite sex. If there was service provider of opposite sex in the nearest health facility they prefer moving to another health centre.

\section{Lack of Confidentiality:}

Lack of confidentiality was considered as one of the barriers, most of the unmarried youth fear of being exposed in the society and do not visit the health facility for sexual health services. They were afraid that if anything came out they would not be able to answer their family.

\section{Poor availability of the services:}

Most of the participants complained about non-availability of proper services and non-availability of qualified service providers at the health posts.

\section{Opinion towards improving the access to services:}

Participants reported, they need information regarding sexual health services, which can be improved by providing youth friendly services as well as should not only be urban centered but also need to be extended to all rural part.

\section{Discussion:}

Perception on existing services:

Our findings revealed that most of the participants, particularly from rural areas were not satisfied with the services provided to them. They felt that most of the services are only available in urban areas and it takes their lot of time to reach the clinics or hospitals in urban areas, whereas the services at rural centers are basic and fewer. The rural participant urged that only few shops provide condoms and other services. Sexual health services were perceived to be neither sufficient nor youth friendly. On the other hand, urban participants of were quite satisfied by the services provided to them because they have good and easy access to various health centers and clinics. Mostly the married females were satisfied with the services provided by the family planning organization. Similar results were obtained among young people in Nepal where urban young men shared that they can easily by condoms as there are many health facilities available. $^{2}$

Barriers to the sexual health service utilization:

Our finding suggests that the major factors influencing the barriers to sexual health services were; discrimination, beliefs of society and feeling of shame towards family norms, lack of information about existing services, poor gender friendly services, lack of privacy, confidentiality and poor availability of the services.

Most of the young people do not feel comfortable to discuss the issues and problems related to sexual health and prefer not to share the problems to their elders and family members. These type of issues are not only common in our Nepal but also in other part of world feeling of shame, fear of disappointments, stigmatization or judgmental by family and community is considered as one of the barriers to access the sexual health services. ${ }^{15-18}$ However, the discrimination felt by our participants of Badi community was not observed in other studies. Lack of information about the sexual health services in our study is another finding they even do not know the facilities available to them to their nearest health centers. Generally young people have limited means of obtaining information. ${ }^{16,19,20}$ In Zambia, young people face greater sexual health related risks than adults, however they are less willing and unable to access services due to lack of awareness and inadequate information around the services available to their localities. $^{21}$ 
The fear of lack of privacy and confidentiality was observed, and participants had fear of being exposed in the society. They claimed that they are afraid that if anything comes out they will not be able to answer their family. Fear of being exposed during health facility visit was also a common barrier among female sex workers in Nepal. 2, 22, 23 Non-qualified service provider at the health services was another obstacle for young people.

Opinion towards improving the access to services:

Most of the participants reported they need information regarding sexual health services, whereas unmarried youth focused on improving the youth friendly services. Participants felt that there should be change in the attitude of the society towards the issues related to sexual health and the services should not only be urban centered but also need to be extended to all rural part.

\section{Limitations:}

Our study has several limitations. The study was conducted only in one district; hence it is difficult to generalize our findings with other areas of the country. Being a multi-ethnic and multi-cultural society of Nepal, it has its own norms and values around the sexuality. Secondly, sex and sex related issues are not discussed openly in Nepal but most of the participants in our study actively discussed and shared their experience.

\section{Conclusions:}

The key barriers to the use of sexual health services among young people of the Badi community in district Dang Nepal do not vary greatly from other young people of the developing and developed countries. The discrimination, beliefs of society and feeling of shame towards family norms, lack of information about existing services, urban area centered, poor gender friendly services, lack of privacy and confidentiality and poor availability of the services were the main barriers observed. Communities should be provided with educational programs on sexual health through community based organization and the establishment of youth friendly service centers with easy access to communities in urban as well as in rural areas would encourage young people to use sexual health services more frequently.

\section{Conflict of interest: None}

\section{References:}

1. Regmi K. Opportunities and Challenges of Sexual Health Services among Young People: A Study in Nepal. Journal of Sexual Medicine 2009;6(2):352-61.
2. Regmi P, Simkhada P, Van Teijlingen ER. Sexual and reproductive health status among young peoples in Nepal: opportunities and barriers for sexual health education and services utilization. Kathmandu Univ Med J 2008;6:24856.

3. Stackpool-Moore L, Bajpai D, Caswell G, Crone Y, Dewar F, Gray G, et al. Linking Sexual and Reproductive Health and Rights and HIV Services for Young People: The Link Up Project. Journal of Adolescent Health 2017;60:S3-S6.

4. Nybladea L, Stocktona M, Nyatob D, Wamoyib J. Perceived, anticipated and experienced stigma: exploring manifestations and implications for young people's sexual and reproductive health and access to care in North-Western Tanzania. Culture, Health \& Sexuality 2017:1-16.

5. Roudsari RL, Javadnoori M, Hasanpour M, Hazavehei SMM, Taghipour A. Socio-cultural challenges to sexual health education for female adolescents in Iran. Iran J Reprod Med 2013;11(2):101-10.

6. Inelmen EM, Sergi G, Girardi A, Coin A, Toffanello ED, Cardin F, et al. The importance of sexual health in the elderly: breaking down barriers and taboos. Aging Clin Exp Res 2012;24(3 Suppl):31-4.

7. Ayalew M, Mengistie B, Semahegn A. Adolescent-parent communication on sexual and reproductive health issues among high school students in Dire Dawa, Eastern Ethiopia: a cross sectional study. Reprod Health 2014;11(1):77.

8. Khatiwada N, Silwal PR, Bhadra R, and Tamang TM. 2013. Sexual and Reproductive Health of Adolescents and Youth In Nepal: Trends and Determinants: Further analysis of the 2011 Nepal Demographic and Health Survey. Calverton, Maryland, USA: Nepal Ministry of Health and Population, New ERA, and ICF International.

9. Youth Speak Out: Advocating for Young People's Sexual and Reproductive Health in Nepal. YUWA, 2012.

10. Central Bureau of Statistics, Kathmandu, Nepal, Jan. 2014.

11. Cox T. The Badi: Prostitution as a social norm among an untouchable caste of west Nepal. CNAS Journal 1992;19(1):51-71.

12. United Nations Resident and Humanitarian Coordinator's Office Field Bulletin: The Badi Community of Nepal. 2012.

13. Mulye TP, Park MJ, Nelson CD, Adams SH, Irwin CE Jr, Brindis CD.Trends in adolescent and young adult health in the United States. J Adolesc Health 2009;45(1):8-24.

14. Stone N, Ingham R, Simkhada P. Knowledge of sexual health issues among unmarried young people in Nepal. Asia-Pacific Population Journal 2003;18(2):33-54.

15. Adhikari R, Tamang J. Premarital sexual behavior among male college students of Kathmandu, Nepal. BMC Public Health 2009;9:241. 
16. Musa GB, Gegbe MAB. External Evaluation Report of Sierra Leone's Youth Reproductive Health Programme (2007-2012).

17. Mbeba RM, Mkuye MS, Magembe GE, Yotham WL, Mellah AO, SB M. Barriers to sexual reproductive health services and rights among young people in Mtwara district, Tanzania: a qualitative study. Pan Afr Med J 2012;Suppl 1.

18. Kaufman MR, Smelyanskaya M, Van Lith LM, Mallalieu EC, Waxman A, Hatzhold K, et al. Adolescent Sexual and Reproductive Health Services and Implications for the Provision of Voluntary Medical Male Circumcision: Results of a Systematic Literature Review. PLoS One 2016;11(3):e0149892.

19. Chen B, Lu YN, Wang HX, Ma QL, Zhao XM, Guo JH, et al. Sexual and reproductive health service needs of university/ college students: updates from a survey in Shanghai, China. Asian J Androl 2008;10(4):607-15.
20. Upreti D, Regmi P, Pant P, Simkhada P. Young people's knowledge, attitude, and behaviour on STI/HIV/AIDS in the context of Nepal: a systematic review. Kathmandu Univ Med J 2009;7(28):383-91.

21. Sialubanje C, Massar K, Hamer DH, Ruiter RA. Reasons for home delivery and use of traditional birth attendants in rural Zambia: a qualitative study. BMC Pregnancy Childbirth 2015;15:216.

22. Ghimire L, Smith WCS, van Teijlingen ER. Utilisation of sexual health services by female sex workers in Nepal. BMC Health Serv Res 2011;11:79.

23. Ghimire L, Smith WCS, van Teijlingen ER, Dahal R, Luitel NP. Reasons for non- use of condoms and self- efficacy among female sex workers: a qualitative study in Nepal. BMC Womens Health 2011;11:42. 